\title{
Investigation of Alkoxysilanes in the Presence of Hydrogen with Ziegler-Natta Catalysts in Ethylene Polymerization
}

\author{
Thanyathorn Niyomthai ${ }^{a}$, Bunjerd Jongsomjit ${ }^{\mathrm{b}}$, and Piyasan Praserthdam ${ }^{\mathrm{c}}{ }^{*}$ \\ Center of Excellence on Catalysis and Catalytic Reaction Engineering, Department of Chemical \\ Engineering, Faculty of Engineering, Chulalongkorn University, Bangkok 10330, Thailand \\ E-mail: aniyomthai.th@gmail.com, bbunjerd.j@chula.ac.th, cpiyasan.p@chula.ac.th (Corresponding \\ author)
}

\begin{abstract}
Effect of hydrogen and alkoxysilanes as external donor were investigated using two commercial Ziegler-Natta catalysts $\left(\mathrm{TiCl}_{4} / \mathrm{MgCl}_{2} \bullet \mathrm{nEtOH}\right.$ and $\mathrm{TiCl}_{4} /$ phthalate type $\left./ \mathrm{MgCl}_{2}\right)$ in ethylene polymerization. These catalysts were analyzed by EDX, FTIR and XRD measurements. Furthermore, catalytic activity was tested. According to the results, when alkoxysilane was introduced into the system, catalytic activity reduced. Compared these two alkoxysilanes, cyclohexylmethyldimethoxysilane (CHMDMS) can decrease activity more than dimethoxydimethylsilane (DMDMS) did. This was because CHMDMS has more bulky hydrocarbon groups than DMDMS. This led to restrict the direction of monomer insertion to active sites. In addition, when hydrogen was added into the system, CHMDMS is more sensitive to hydrogen than DMDMS. However, CHMDMS showed lower hydrogen response than DMDMS with increased hydrogen concentration. This was owing to its hydrogen sensitivity. Among the two catalysts, catalyst having internal donor can decrease sensitivity of catalyst activity in the system with hydrogen. The obtained polymers were further characterized by DSC and GPC.
\end{abstract}

Keywords: Ziegler-Natta catalyst, ethylene polymerization, external donor, alkoxysilanes.

ENGINEERING JOURNAL Volume 21 Issue 7

Received 11 April 2017

Accepted 9 May 2017

Published 29 December 2017

Online at http:/ /www.engj.org/

DOI:10.4186/ej.2017.21.7.171 


\section{Introduction}

At present, Ziegler-Natta (ZN) catalysts, which use $\mathrm{MgCl}_{2}$ as support, are still the most important catalytic systems to achieve high active catalyst for the polyolefins production [1]. Refer to hydrogen, it is an effective chain transfer agent, which is generally employed to reduce and control the molecular weight of polymer in olefin polymerization. Hydrogen can be effectively applied in various polymerization conditions [2]. However, influence of hydrogen on catalyst activity is difficult to predict and varies depending on types of catalyst, monomer, and electronic donor. For example, hydrogen normally reduces rate of ethylene polymerization, but it increases rate of propylene polymerization for ZN catalyst [3, 4]. However, Zhang et al. studied effect of hydrogen in ethylene/1-hexene copolymerization in the presence of internal donor. They found that hydrogen can improve the catalyst activity in ethylene/1-hexene copolymerization when it presents in a small concentration [5]. At this point, the effect of hydrogen is still unclear, but it is interesting to investigate further.

There are many methods to improve catalyst like mechanical and chemical treatment [6-10]. The addition of Lewis base is one of the chemical routes to obtain the high active catalyst. Currently, the fourth generation of $\mathrm{ZN}$ catalyst is mostly synthesized and investigated in industry and academic aspects, especially in propylene polymerization. This catalyst generation is consisted of $\mathrm{TiCl}_{4} / \mathrm{MgCl}_{2}$ supported catalyst, internal and external donor (Lewis bases). Internal donor is added during the catalyst synthesis, while external donor is added during polymerization reaction. The main functions of external donor are to replace the lost internal donor, which is removed from the alkylation and/or complexation reaction with cocatalyst and protect the stereoregularity of active sites in propylene polymerization [11,12]. In part of ethylene polymerization, Zhang et al. observed that electron donor has a large effect not only on the isospecificity, but also on the catalyst activity, molecular weight and molecular weight distribution in ethylene homopolymerization [13]. They found that the catalyst activity with various kinds of internal donor decreased in the following order: none $>$ succinate $>$ phthalate $>$ diether, while the structure of alkoxysilane used as external donor did not show the significant effect on the catalyst activity. Moreover, the molecular weight and molecular weight distribution of polyethylene were less affected by external donor addition. Furthermore, Zhang et al. studied the effect of phthalic anhydride and anisole as internal donor in ethylene/1-hexene copolymerization with Ziegler-Natta catalyst [5]. The results showed that the addition of internal donor can improve the activity. As described previously, the various kinds of electron donors were used in olefin polymerization such as monoester, diester, alkoxysilane, diether and etc [11, 14]. Recently, phthalate based type or diester and alkoxysilane are typically used as internal and external donor, respectively [15]. Among various $\mathrm{R}_{1} \mathrm{R}_{2} \mathrm{Si}(\mathrm{OMe})_{2}$ types of external donor, cyclohexylmethyldimethoxysilane (CHMDMS) is more frequently used due to its effective performance to enhance the isotacticity of polypropylene without sacrificing the catalyst activity [2]. By the way, ethanol is one kind of Lewis base, which is usually used to improve $\mathrm{MgCl}_{2}$ crystal structure [16]. As mentioned previously, Lewis bases were studied in many aspects in propylene polymerization. For example, the combination of internal and external donor, the mixed internal donors and/or mixed external donors [17, 18] including the different ratios of external donor to catalyst were investigated. However, the effect of external donor in ethylene polymerization is still open for discussion and less mentioned in the literature. Therefore, the aim of this work was to study the effect of alkoxysilane as external donor on catalytic activity using two commercial ZN catalysts with and without internal donor in the presence of hydrogen including thermal properties, molecular weight and its distribution of polymer in ethylene polymerization.

\section{Experimental}

\subsection{Chemicals}

All chemicals and operation steps were carried out under nitrogen atmospheres using a standard glove box and Schlenk techniques. Two commercial $\mathrm{MgCl}_{2}$-supported Ziegler-Natta catalysts $\left[\mathrm{TiCl}_{4} / \mathrm{MgCl}_{2} \bullet \mathrm{nEtOH}\right.$ (Cat-A) and $\mathrm{TiCl}_{4} /$ phthalate type $/ \mathrm{MgCl}_{2}$ (Cat-B)], triethylaluminum (TEA) as cocatalyst and $\mathrm{n}$-hexane as medium solvent were donated by Thai Polyethylene Co., Ltd. Ethylene polymerization grade, hydrogen and nitrogen were purchased from Linde Co., Ltd. and used without any purification. Cyclohexylmethyldimethoxysilane (CHMDMS) and dimethoxydimethylsilane (DMDMS) as external donors were purchased from Alfa Aesar and Sigma-Aldrich, respectively. These external donors were used as received. 


\subsection{Ethylene Polymerization}

\subsubsection{Effect of $\mathrm{H}_{2} / \mathrm{C}_{2} \mathrm{H}_{4}$ molar ratio}

Ethylene polymerization was performed in a $2 \mathrm{~L}$ autoclave reactor at $80^{\circ} \mathrm{C}$ for $1 \mathrm{~h}$. The reactor was evacuated and purged by nitrogen for many times. After that, $1 \mathrm{~L}$ of $\mathrm{n}$-hexane and a designated amount of triethylaluminum $([\mathrm{Al}] /[\mathrm{Ti}]=140)$ and external donor $([\mathrm{Al}] /[\mathrm{Si}]=10)$ were added under stirring into the reactor. Then, catalyst slurry was added into the autoclave to start the polymerization. Next, 1 bar of nitrogen was filled and followed by the desired amount of hydrogen $\left(\mathrm{H}_{2} / \mathrm{C}_{2} \mathrm{H}_{4}\right.$ molar ratio $=0,0.08,0.20$ and 0.60$)$. Ethylene was continuously supplied to the reactor to maintain the total pressure of 8 bars during the polymerization time of $1 \mathrm{~h}$. The obtained polymer was dried at room temperature overnight.

\subsection{Characterizations}

\subsubsection{Inductively couple plasma (ICP)}

Elemental composition in bulk was determined using inductively couple plasma optical emission spectrometer (ICP-OES optima 2100 DV from Perkin Elmer). The catalyst sample was digested with $5 \mathrm{~mL}$ of hydrochloric acid, and then diluted with DI water.

\subsubsection{Fourier transforms infrared spectroscopy (FTIR)}

The interaction between catalyst and support was identified using Fourier transforms infrared spectroscopy with Nicolet 6700 FT-IR spectrometer. The catalyst powder was prepared on $\mathrm{NaCl}$ disk in the glove box. The measurement in transmittance values was analyzed under nitrogen atmosphere in the range of scanning between 400 to $4000 \mathrm{~cm}^{-1}$ for scanning of 400 times with the resolution of 4 and number of scan of 500 .

\subsubsection{X-ray diffraction (XRD)}

Phases and crystallinity of the catalyst and $\mathrm{MgCl}_{2}$ support were identified using Bruker of $\mathrm{D} 8$ Advance. The specimen was prepared on holder under argon atmosphere. Diffraction patterns were analyzed under nitrogen atmosphere with the scanning speed of 0.3 second/step and step size of 0.02 in the $2 \theta$ range of 10 80 degrees.

\subsubsection{Scanning electron microscopy (SEM) and energy dispersive x-ray spectroscopy (EDX)}

Morphologies of catalyst and its elemental distribution were investigated under nitrogen atmosphere using SEM and EDX, respectively. The SEM of Hitachi mode S-3400N was applied, while the EDX was performed using Link Isis series 300 program.

\subsubsection{Gel permeation chromatography (GPC)}

A high temperature GPC (Waters $150{ }^{\circ} \mathrm{C}$ ) equipped with a viscometric detector was conducted to measure molecular weight and molecular weight distributions of polymers. 1, 2, 4-trichlorobenzene was used as solvent. The polymer samples before analysis with GPC were dissolved in 1, 2, 4-trichlorobenzene at $160^{\circ} \mathrm{C}$ for $90 \mathrm{~min}$ and then filtered polymers to prevent clogging.

\subsubsection{Differential scanning calorimetry (DSC)}

Differential scanning calorimetry analysis was conducted on a TA instruments SDT Q600 V8.1 Build 99 thermal analyzer to determine the melting temperature $\left(\mathrm{T}_{\mathrm{m}}\right)$ and percentage of crystallinity $\left(\chi_{\mathrm{c}}\right)$ of polyethylene. A heating rate of $10{ }^{\circ} \mathrm{C} / \mathrm{min}$ in the range of temperature $=30-600{ }^{\circ} \mathrm{C}$ was employed in this measurement. The crystallinity of polymers was calculated by the following equation: 


$$
X c=\frac{\Delta H}{\Delta H^{\circ}} \times 100
$$

where $\Delta \mathrm{H}$ is heat of fusion of polyethylene sample; $\Delta \mathrm{H}^{\circ}$ is the heat of fusion of linear polyethylene equals to $290 \mathrm{~J} / \mathrm{g}[19]$.

\section{Results and Discussion}

\subsection{Catalyst Characterization}

\subsubsection{ICP and EDX measurements of catalysts}

The elemental composition of catalyst was determined by ICP as reported in Table 1. It shows that Cat-A and Cat-B contain $3.79 \mathrm{wt} \%$ of $\mathrm{Ti}$ and $2.47 \mathrm{wt} \%$ of $\mathrm{Ti}$, respectively. However, the Ti/ $\mathrm{Mg}$ ratios in bulk of them were similar. Furthermore, EDX analysis was applied to identify the elemental composition on surface of catalyst as presented in Table 2. It can be seen that Ti content on catalyst surface is higher than Ti content in bulk measured by ICP technique. It indicated that most Ti active sites were located on the surface of catalyst more than in the catalyst pores. However, the ratios of $\mathrm{Ti} / \mathrm{Mg}$ of these catalysts were also similar. Cat-A showed the $\mathrm{Ti} / \mathrm{Mg}$ ratio of 0.10 , while Cat-B showed the $\mathrm{Ti} / \mathrm{Mg}$ ratio of 0.12 .

Table 1. The elemental composition of the commercial catalysts.

\begin{tabular}{ccccc}
\hline \multirow{2}{*}{ Catalyst } & \multicolumn{3}{c}{ Elemental composition ${ }^{\mathbf{a}}\left(\mathbf{w t} \mathbf{}^{\mathbf{0}}\right)$} & $\mathrm{Ti} / \mathbf{M g}$ \\
& $\mathbf{T i}$ & $\mathbf{M g}$ & $\mathbf{C l}$ & $\mathbf{( m o l} / \mathbf{m o l})$ \\
\hline Cat-A & 5.09 & 24.99 & 67.44 & 0.10 \\
Cat-B & 5.26 & 23.07 & 71.27 & 0.12 \\
\hline
\end{tabular}

(a) Determined by ICP measurement

Table 2. The elemental composition on surface of catalysts by EDX measurement.

\begin{tabular}{|c|c|c|c|}
\hline \multirow[b]{2}{*}{ Catalyst } & \multicolumn{2}{|c|}{ Elemental composition ${ }^{a}(w t \%)$} & \multirow{2}{*}{$\begin{array}{c}\mathrm{Ti} / \mathrm{Mg} \\
(\mathrm{mol} / \mathrm{mol})\end{array}$} \\
\hline & $\mathbf{T i}$ & $\mathbf{M g}$ & \\
\hline Cat-A & 3.79 & 14.89 & 0.11 \\
\hline Cat-B & 2.47 & 16.66 & 0.08 \\
\hline
\end{tabular}

(a) Determined by EDX analysis

\subsubsection{FT-IR spectroscopy of catalysts}

IR identification has been widely used to identify the interaction between $\mathrm{TiCl}_{4}$ and $\mathrm{MgCl}_{2}$ support. According to Fig. 1, IR spectra of all catalysts are presented in the range of 3900-500 $\mathrm{cm}^{-1}$. The analysis of the IR spectrum of Cat-A revealed that the alcoholate peak was found in the range of $3100-3700 \mathrm{~cm}^{-1}$ corresponding to $\mathrm{O}-\mathrm{H}$ stretching [8]. Moreover, the bands at $2874-2983 \mathrm{~cm}^{-1}$ and $1266-1476 \mathrm{~cm}^{-1}$ corresponded to $\mathrm{C}-\mathrm{H}$ stretching, while the vibration at $1095 \mathrm{~cm}^{-1}$ corresponded to $\mathrm{C}-\mathrm{O}$ stretching [9]. This IR spectrum of Cat-A is in good agreement with the report by Parada $e t$ al [8]. In part of Cat-B, it also showed the band around $2800-3000 \mathrm{~cm}^{-1}$ and $1273-1495 \mathrm{~cm}^{-1}$ corresponding to $\mathrm{C}-\mathrm{H}$ stretching. The characteristic peaks of ester occur at $1696-1758 \mathrm{~cm}^{-1}$ and $936-1154 \mathrm{~cm}^{-1}$. Moreover, the aromatic ring stretching is located at $1588 \mathrm{~cm}^{-1}$, while the vibration is at $737 \mathrm{~cm}^{-1}$ indicating the ortho aromatic ring [20]. As a result, it means that there is phthalate type as internal donor in Cat-B. 


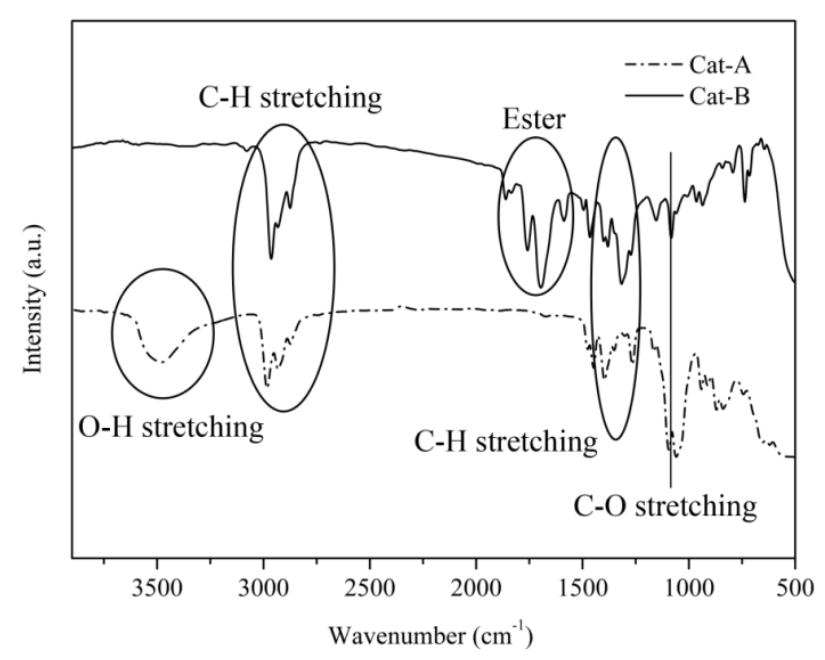

Fig. 1. IR spectra of Cat-A and Cat-B.

\subsubsection{XRD measurement of catalysts}

The XRD patterns of $\alpha-\mathrm{MgCl}_{2}$ support and catalysts in the range of 10-80 degree are presented in Fig. 2 . The characteristic peak of anhydrous $\mathrm{MgCl}_{2}$ showed the sharp peaks at $2 \theta=14.4^{\circ}, 29.7^{\circ}, 34.3^{\circ}$, and $49.5^{\circ}$. Sharp peak at $2 \theta=14.4^{\circ}$ was defined as the stacking of $\mathrm{Cl}-\mathrm{Mg}-\mathrm{Cl}$ triple layers along the crystallographic direction. While three peaks at $2 \theta=29.7^{\circ}, 34.3^{\circ}$ and $49.5^{\circ}$ were found and assigned to be the stacking faults of the triple layers. The peaks at $2 \theta=34.3^{\circ}$ and $49.5^{\circ}$ represented the (104) and (110) plane, respectively [21, 22]. Cat-A and Cat-B exhibited the reduction of intensity in all peaks of $\alpha-\mathrm{MgCl}_{2}$. This is because $\alpha-\mathrm{MgCl}_{2}$ turned into the active $\delta-\mathrm{MgCl}_{2}$ resulting in the disappearance of peak at $2 \theta=14.4^{\circ}, 29.7^{\circ}, 34.3^{\circ}$ and $49.5^{\circ}$. This indicated that the $\delta-\mathrm{MgCl}_{2}$ support has a single $\mathrm{Cl}-\mathrm{Mg}-\mathrm{Cl}$ structural layers (monolayers) [22]. Therefore, the modification of $\alpha-\mathrm{MgCl}_{2}$ form into active $\delta-\mathrm{MgCl}_{2}$ form led to the increase in the interplanar distance or decrease in $2 \theta$ value [23]. As a result, the crystallinity was low.

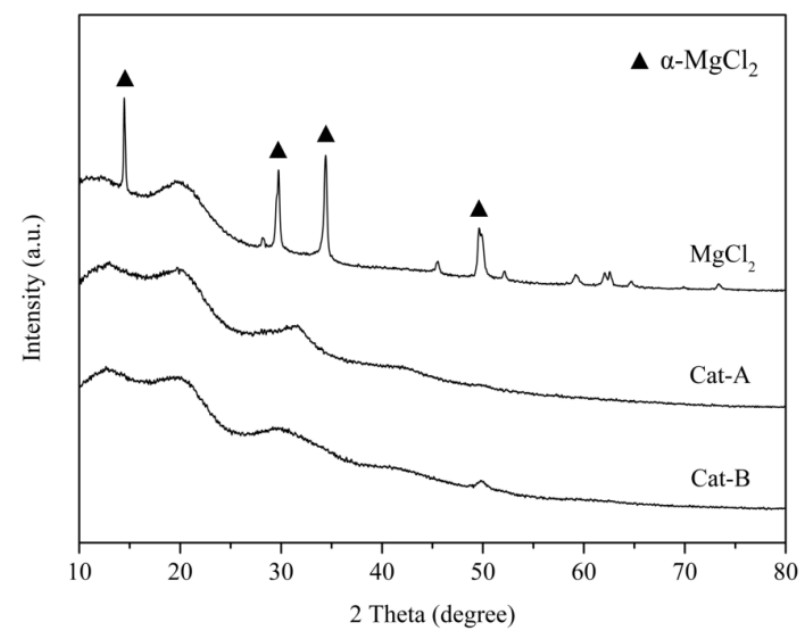

Fig. 2. XRD patterns of $\mathrm{MgCl}_{2}$ support and catalyst.

\subsubsection{SEM images of catalysts}

As seen in Fig. 3, morphology of catalyst was investigated by SEM technique. The result revealed that Cat-A is in irregular shapes, whereas Cat-B is quite uniformly spherical shape. 


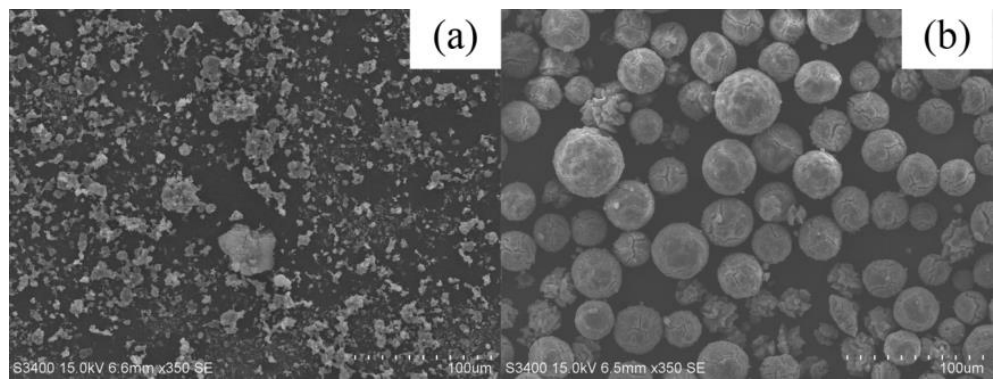

Fig. 3. SEM images of catalysts: (a) Cat-A and (b) Cat-B.

\subsection{Catalytic Activity}

According to Table 3 , it is seen that catalytic activity was lower when adding external donor. This is because electron donor can form complex with both cocatalyst and active sites [2, 12, 18, 24]. As a consequence, the content of active cocatalyst, which can activate the active site was lower. Therefore, the efficiency of the formation of active site was reduced. In addition, CHMDMS and DMDMS have the bulky substituents, which cause the steric hindrance to neighborhood active sites. This led to restrict the direction of monomer insertion. Thus, this caused the decrease in activity for both catalysts [25]. However, Zhang et al. reported that alkoxysilane requires the bulky hydrocarbon groups to prevent the removal of silane from the surface of catalyst via the complexation with cocatalyst $[2,12,15]$. In this work, CHMDMS can reduce the catalytic activity more than DMDMS did. It may be due to the fact that cyclohexyl group of CHMDMS has more bulkiness than methyl group of DMDMS resulting in the decrease in monomer insertion as mentioned previously. Moreover, Cat-A exhibited the decrease in activity ratio more than Cat-B when external donor was added. It is probably that alkoxysilane has some poisoning effect on non-stereospecific active sites for Cat-A $[12,13]$. In case of Cat-B, it has phthalate type as internal donor, which can turn less stereospecific active site into the more stereospecific one. However, almost internal donor can be easily removed from the catalysts surface through complexation with cocatalyst $[12,18]$. By the way, Cat-B has external donor, which can replace the lost internal donor. As a consequence, Cat-B showed higher activity ratio than Cat-A but, it still lower than that of without external donor. This is because alkoxysilane has a slightly deactivation effect on catalyst [26].

As it has been already known, hydrogen is commonly used as an effective chain transfer agent to reduce the molecular weight of polymer in olefin polymerization $[2,27]$. Therefore, the polymer molecular weight can be controlled by changing the volume of added hydrogen [2]. According to Table 3, hydrogen was introduced into the system. It was found that both catalysts exhibited lower activity than that in the system without hydrogen addition. This is because hydrogen can block active site for polymerization. This caused the reduction of opportunity of ethylene monomer to the catalyst active sites and favoured the termination reaction [28]. It means that hydrogen can suppress the ethylene polymerization rate due to the formation of Ti- $\mathrm{H}$ bond. This Ti-H bond is less active and can generate the stabilized $\mathrm{Ti}^{-} \mathrm{C}_{2} \mathrm{H}_{5}$ bond further [27]. Thus, the activity decreased when hydrogen increased for both catalysts in ethylene polymerization. Moreover, when external donor was added in period of $\mathrm{H}_{2} / \mathrm{C}_{2} \mathrm{H}_{4}$ molar ratio at $0-0.20$, compared between the two external donors, much more hydrogen was needed when DMDMS was used as external donor. For example in case of Cat-B, small amount addition of hydrogen at $\mathrm{H}_{2} / \mathrm{C}_{2} \mathrm{H}_{4}$ molar ratio of 0.08 exhibited $14 \%$ decrease in activity ratio for CHMDMS, while DMDMS required more hydrogen amounts at $\mathrm{H}_{2} / \mathrm{C}_{2} \mathrm{H}_{4}$ molar ratio of 0.20 to gain the decrease in activity ratio of $13 \%$. It means that CHMDMS is more sensitive to hydrogen [2]. However, in period of higher $\mathrm{H}_{2} / \mathrm{C}_{2} \mathrm{H}_{4}$ molar ratio at $0.20-0.60$, it showed the different result in hydrogen response compared with less hydrogen system. It was seen that there was a slight change in activity for both catalysts when CHMDMS was employed as external donor. It indicated that CHMDMS showed lower hydrogen response than DMDMS did in the higher hydrogen concentration. From the previous result, CHMDMS is sensitive to hydrogen more than DMDMS. Therefore, when hydrogen was increased, most of active sites, when CHMDMS acted as external donor, can react quickly with hydrogen and turn into inactive sites. As a consequence, hydrogen response of CHMDMS was lower, whereas DMDMS showed higher hydrogen response than CHMDMS due to its less sensitive to hydrogen. Compare between these two catalysts, the results implied that the bulkiness of external donor showed the significant effect on the activity of the internal donor absent catalyst in the system having hydrogen, while the catalyst having internal donor 
was less influenced by the structure of external donor. This was because the addition of internal donor decreased sensitivity of catalyst activity to external donor. This result is in good agreement with that of Zhang et al [5]. They reported that the addition of phthalic anhydride or anisole as internal donor can depress the sensitivity of catalyst activity to hydrogen in ethylene /1-hexene copolymerization.

Table 3. Catalytic activity of the commercial catalysts in ethylene polymerization.

\begin{tabular}{|c|c|c|c|c|c|}
\hline Catalyst & $\begin{array}{c}\text { External } \\
\text { donor }\end{array}$ & {$\left[\mathbf{H}_{2}\right] /\left[\mathbf{C}_{2} \mathbf{H}_{4}\right]$} & $\begin{array}{c}\text { Activity } \\
\left(\mathrm{kgPE} / \mathrm{gTi}{ }^{*} \mathrm{~h}\right)\end{array}$ & $\begin{array}{c}\text { Activity ratio } \\
\text { without } \mathbf{H}_{2}\end{array}$ & $\begin{array}{c}\text { Activity ratio } \\
\text { with } \mathrm{H}_{2}\end{array}$ \\
\hline \multirow{12}{*}{ Cat-A } & \multirow[t]{4}{*}{ 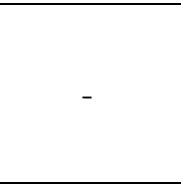 } & 0 & 845 & 1.00 & 1.00 \\
\hline & & 0.08 & 608 & - & 0.72 \\
\hline & & 0.20 & 606 & - & 0.72 \\
\hline & & 0.60 & 511 & - & 0.61 \\
\hline & \multirow{4}{*}{ CHMDMS } & 0 & 253 & 0.30 & 1.00 \\
\hline & & 0.08 & 110 & - & 0.43 \\
\hline & & 0.20 & 110 & - & 0.43 \\
\hline & & 0.60 & 96 & - & 0.38 \\
\hline & \multirow{4}{*}{ DMDMS } & 0 & 313 & 0.37 & 1.00 \\
\hline & & 0.08 & 259 & - & 0.83 \\
\hline & & 0.20 & 235 & - & 0.75 \\
\hline & & 0.60 & 184 & - & 0.59 \\
\hline \multirow{12}{*}{ Cat-B } & \multirow{4}{*}{ - } & 0 & 558 & 1.00 & 1.00 \\
\hline & & 0.08 & 489 & - & 0.88 \\
\hline & & 0.20 & 430 & - & 0.77 \\
\hline & & 0.60 & 282 & - & 0.51 \\
\hline & \multirow{4}{*}{ CHMDMS } & 0 & 304 & 0.54 & 1.00 \\
\hline & & 0.08 & 262 & - & 0.86 \\
\hline & & 0.20 & 190 & - & 0.62 \\
\hline & & 0.60 & 211 & - & 0.69 \\
\hline & \multirow{4}{*}{ DMDMS } & 0 & 330 & 0.59 & 1.00 \\
\hline & & 0.08 & 294 & - & 0.89 \\
\hline & & 0.20 & 287 & - & 0.87 \\
\hline & & 0.60 & 177 & - & 0.53 \\
\hline
\end{tabular}

Condition: Polymerization was performed in $2 \mathrm{~L}$ autoclave, $[\mathrm{Ti}]=0.008 \mathrm{mmol}$ for all catalysts, $[\mathrm{Al}] /[\mathrm{Ti}]=$ $140,[\mathrm{Al}] /[\mathrm{Si}]=10$, co-catalyst $=$ TEA, polymerization time $=1 \mathrm{~h}$, reaction temperature $=80^{\circ} \mathrm{C}$, desired amount of $\mathrm{H} 2 / \mathrm{C} 2 \mathrm{H} 4$ molar ratio $=0,0.08,0.20$ and 0.60 , under nitrogen, desired amount of hydrogen and ethylene partial pressure of 1,X,7-X bars, respectively.

\subsection{Effect of Hydrogen on Polymer Properties}

Polymer molecular weight and molecular weight distributions were determined by GPC as presented in Table 4. The result showed that when hydrogen was introduced, the melting point decreased and crystallinity of polymer increased. This is due to the fact that the added hydrogen acts as a chain transfer agent to reduce the polymer molecular weight resulting in lower molecular weight and melting temperature of polymer [28]. In addition, Sperling et al. reported that polymer having lower molecular weight will have lower surface area. It indicated lower physical attraction between the polymer chains and low melting point [29]. In case of crystallinity of polymer, since hydrogen is always employed as chain transfer agent, hydrogen will block catalyst active site as mentioned previously. This results in the reduction of polymerization rate. Then, the crystallinity was improved $[28,30]$. The MWD of polymer remained significantly unchanged with hydrogen concentration [31, 32]. 
Table 4. Influences of alkoxysilanes and hydrogen on polyethylene properties.

\begin{tabular}{|c|c|c|c|c|c|c|c|}
\hline Catalyst & External donor & {$\left[\mathrm{H}_{2}\right] /\left[\mathrm{C}_{2} \mathrm{H}_{4}\right]$} & $\mathrm{T}_{\mathrm{m}}\left({ }^{\circ} \mathrm{C}\right)^{\mathrm{a}}$ & $\chi_{c}(\%)^{a}$ & $\begin{array}{l}\mathrm{Mw}^{\mathrm{b}} \times 10^{-3} \\
(\mathrm{~g} / \mathrm{mol})\end{array}$ & $\begin{array}{l}\mathrm{Mn}^{\mathrm{b}} \times 10^{-3} \\
(\mathrm{~g} / \mathrm{mol})\end{array}$ & MWD $^{\mathrm{b}}$ \\
\hline \multirow{12}{*}{ Cat-A } & \multirow{4}{*}{-} & 0 & 134.0 & 55.3 & - & - & - \\
\hline & & 0.08 & 130.5 & 62.3 & 317 & 33 & 9.7 \\
\hline & & 0.20 & 129.9 & 58.3 & 257 & 29 & 8.8 \\
\hline & & 0.60 & 128.9 & 59.1 & 150 & 16 & 9.6 \\
\hline & \multirow{4}{*}{ CHMDMS } & 0 & 134.8 & 66.8 & - & - & - \\
\hline & & 0.08 & 132.0 & 73.3 & 501 & 57 & 8.8 \\
\hline & & 0.20 & 130.7 & 73.8 & 308 & 36 & 8.7 \\
\hline & & 0.60 & 128.9 & 74.5 & 154 & 20 & 7.9 \\
\hline & \multirow{4}{*}{ DMDMS } & 0 & 134.4 & 65.2 & - & - & - \\
\hline & & 0.08 & 131.2 & 69.8 & 417 & 41 & 10.1 \\
\hline & & 0.20 & 131.2 & 75.5 & 347 & 40 & 8.7 \\
\hline & & 0.60 & 128.5 & 71.1 & 133 & 20 & 6.8 \\
\hline \multirow{12}{*}{ Cat-B } & \multirow{4}{*}{-} & 0 & 130.4 & 52.9 & - & - & - \\
\hline & & 0.08 & 131.6 & 57.8 & 475 & 51 & 9.4 \\
\hline & & 0.20 & 130.2 & 56.9 & 295 & 32 & 9.2 \\
\hline & & 0.60 & 128.1 & 60.6 & 130 & 17 & 7.6 \\
\hline & \multirow{4}{*}{ CHMDMS } & 0 & 135.4 & 55.8 & - & - & - \\
\hline & & 0.08 & 132.4 & 59.3 & 493 & 63 & 7.8 \\
\hline & & 0.20 & 130.6 & 56.7 & 269 & 35 & 7.7 \\
\hline & & 0.60 & 128.4 & 62.7 & 239 & 20 & 11.3 \\
\hline & \multirow{4}{*}{ DMDMS } & 0 & 135.0 & 66.4 & - & - & - \\
\hline & & 0.08 & 132.0 & 70.8 & 420 & 69 & 6.1 \\
\hline & & 0.20 & 131.0 & 68.8 & 328 & 51 & 6.4 \\
\hline & & 0.60 & 128.6 & 71.5 & 129 & 13 & 6.7 \\
\hline
\end{tabular}

(a) Determined by DSC

(b) Determined by GPC

Condition: Polymerization was performed in $2 \mathrm{~L}$ autoclave, $[\mathrm{Ti}]=0.008 \mathrm{mmol}$ for all catalysts, $[\mathrm{Al}] /[\mathrm{Ti}]=$ $140,[\mathrm{Al}] /[\mathrm{Si}]=10$, co-catalyst $=$ TEA, polymerization time $=1 \mathrm{~h}$, reaction temperature $=80^{\circ} \mathrm{C}$, desired amount of $\mathrm{H}_{2} / \mathrm{C}_{2} \mathrm{H}_{4}$ molar ratio $=0,0.08,0.20$ and 0.60 , under nitrogen, desired amount of hydrogen and ethylene partial pressure of $1, \mathrm{X}, 7-\mathrm{X}$ bars, respectively.

\subsection{Effect of External Donor on Polymer Properties}

From Table 4, it can be seen that the addition of alkoxysilane as external donor can improve molecular weight of polymer [24, 25]. This results in a slight increase in melting point of polymer [28]. Furthermore, alkoxysilane can also enhance crystallinity, but it has no significant change in MWD [13, 26].

\section{Conclusion}

In conclusion, the addition of alkoxysilane as external donor can decrease the activity for Cat-A and Cat-B. This is because electron donor can form complex with cocatalyst and active sites resulting in the decrease in efficiency of the active site formation. CHMDMS can decrease the activity more than DMDMS did. This may be due to the fact that CHMDMS has bulkier hydrocarbon groups than DMDMS. As a consequence, CHMDMS can restrict the directions of monomer insertion to active sites more than DMDMS. When hydrogen was added into the system, catalytic activity reduced. This is because ethylene polymerization rate was suppressed and chain termination by hydrogen was occurred. In addition, when hydrogen and alkoxysilane were added into the system, CHMDMS is more sensitive to hydrogen resulting in higher hydrogen response than DMDMS did in less hydrogen concentration system. While in the higher hydrogen concentration, CHMDMS showed lower hydrogen response than DMDMS due to its higher sensitive to hydrogen. In part of polymer properties, the molecular weight decreased with hydrogen concentration. This 
results in a decrease of melting point and the increase in crystallinity of polyethylene. MWD of polymer is independent with hydrogen concentration. Moreover, when CHMDMS or DMDMS was added into the system, it can enhance the molecular weight and slightly increase melting point including crystallinity of polymer, but it has no significant change in MWD.

\section{Acknowledgements}

The authors thank the Royal Golden Jubilee Ph.D. scholarship from Thailand Research Fund (PHD/0236/2553) and the Ratchadapisek Sompoch Endowment Fund (2016), Chulalongkorn University (CU-59-045-EN). We would like to extend our thankful to Thai Polyethylene Co., Ltd. for GPC measurement.

\section{References}

[1] N. Kashiwa, "The discovery and progress of $\mathrm{MgCl}_{2}$-supported $\mathrm{TiCl}_{4}$ catalysts," J. Polym. Sci., Part A: Polym. Chem., vol. 42, pp. 1-8, 2004.

[2] B. Zhang, Z. Fu, Z. Fan, P. Phiriyawirut, and S. Charoenchaidet, "Preparation and characterization of high MFR polypropylene and polypropylene/poly (ethylene-co-propylene) in-reactor alloys," J. Polym. Sci., vol. 133, no. 8, 2016.

[3] M. C. Sacchi, F. Forlini, I. Tritto, and P. Locatelli, "Stereochemistry of the initiation step in ZieglerNatta catalysts containing dialkyl propane diethers: A tool for distinguishing the role of internal and external donors," Macromol Symp., vol. 89, no. 1, pp. 91-100, 1995.

[4] T. Jiang, L. N. Zhao, M. J. Luo, H. X. Chen, G. L. Mao, C. G. Cao, and Y. N. Ning, "High activity and good hydrogen response silica-supported Ziegler-Natta catalyst for ethylene polymerization," Chin. J. Polym. Sci., vol. 30, pp. 561-567, 2012.

[5] L. Zhang, L. Fan, Z. Fan, and Z. Fu, "Dependence of comonomer effect and hydrogen effect on internal donor in ethylene/1-hexene copolymerizations with $\mathrm{MgCl}_{2}$-supported catalysts," e-Polymers, vol. 10, pp. 167-176, 2010.

[6] J. S. Chung, J. H. Choi, I. K. Song, and W. Y. Lee, "Effect of ethanol treatment in the preparation of $\mathrm{MgCl}_{2}$ support for the propylene polymerization catalyst," Macromolecules, vol. 28, pp. 1717-1718, 1995.

[7] J. H. Choi, J. S. Chung, H. W. Shin, I. K. Song, and W. Y. Lee, "The effect of alcohol treatment in the preparation of $\mathrm{MgCl}_{2}$ support by a recrystallization method on the catalytic activity and isotactic index for propylene polymerization," Eur. Polym. J., vol. 32, pp. 405-410, 1996.

[8] A. Parada, T. Rajmankina, and J. Chirinos, "Study of the $\mathrm{MgCl}_{2}$ recrystallization conditions on ZieglerNatta catalyst properties," Polym. Bull., vol. 43, pp. 231-238, 1999.

[9] D. T. Magalhães, O. Do Coutto Filho, and F. Coutinho, "Ziegler-natta catalyst for ethylene and propylene polymerization supported on adducts of magnesium chloride with methyl and ethyl alcohols," Eur. Polym. J., vol. 27, pp. 827-830, 1991.

[10] P. Pokasermsong and P. Praserthdam, "Comparison of activity of Ziegler-Natta catalysts prepared by recrystallization and chemical reaction methods towards polymerization of ethylene," Chem. Eng. J., vol. 13, pp. 57-64, 2009.

[11] B. Liu, T. Nitta, H. Nakatani, and M. Terano, "Stereospecific nature of active sites on $\mathrm{TiCl}_{4} / \mathrm{MgCl}_{2}$ Ziegler-Natta catalyst in the presence of an internal electron donor," Macromol. Chem. Phy., vol. 204, pp. 395-402, 2003.

[12] M. C. Sacchi, F. Forlini, I. Tritto, P. Locatelli, G. Morini, L. Noristi, and E. Albizzati, "Polymerization stereochemistry with Ziegler-Natta catalysts containing dialkylpropane diethers: A tool for understanding internal/external donor relationships," Macromolecules, vol. 29, pp. 3341-3345, 1996.

[13] H. X. Zhang, Y. J. Shin, D. H. Lee, and K. B. Yoon, "Preparation of ultra high molecular weight polyethylene with $\mathrm{MgCl}_{2} / \mathrm{TiCl}_{4}$ catalyst: Effect of internal and external donor on molecular weight and molecular weight distribution," Polym. Bull., vol. 66, pp. 627-635, 2011.

[14] N. Cui, Y. Ke, H. Li, Z. Zhang, C. Guo, Z. Lv, and Y. Hu, "Effect of diether as internal donor on $\mathrm{MgCl}_{2}$-supported Ziegler-Natta catalyst for propylene polymerization,” J. Appl. Polym. Sci., vol. 99, pp. 1399-1404, 2006. 
[15] J. C. Chadwick, G. Morini, G. Balbontin, I. Camurati, J. J. Heere, I. Mingozzi, and F. Testoni, "Effects of Internal and External Donors on the Regio-and Stereoselectivity of Active Species in $\mathrm{MgCl}_{2}-$ supported catalysts for propene polymerization," Macromol. Chem. Phys., vol. 202, pp. 1995-2002, 2001.

[16] K. Bosowska and M. Nowakowska, "The roles for a Lewis base and $\mathrm{MgCl}_{2}$ in third-generation ZieglerNatta catalysts," J. Appl. Polym. Sci., vol. 69, pp. 1005-1011, 1998.

[17] S. Hakim, M. Nekoomanesh, and A. Shahrokhinia, "The effect of mixed and individual silane external donors on the stereo-defect distribution, active sites and properties of polypropylene synthesized with fourth generation Ziegler-Natta catalyst," Polym Sci Ser A. Chem Phys., vol. 57, pp. 573-580, 2015.

[18] P. Li, S. Tu, T. Xu, Z. Fu, and Z. Fan, "The influence of combined external donor and combined cocatalyst on propylene polymerization with a $\mathrm{MgCl}_{2}$-supported Ziegler-Natta catalyst in the presence of hydrogen," J. Appl. Polym. Sci., vol. 132, no. 12, 2014.

[19] W. Phiwkliang, B. Jongsomjit, and P. Praserthdam, "Effect of $\mathrm{ZnCl}_{2}$-and $\mathrm{SiCl}_{4}$-doped $\mathrm{TiCl}_{4} / \mathrm{MgCl}_{2} / \mathrm{THF}$ catalysts for ethylene polymerization," J. Appl. Polym. Sci., vol. 130, pp. 1588-1594, 2013.

[20] F. Higgins, "Rapid and reliable phthalate screening in plastics by portable FTIR spectroscopy," Agilent Technologies, Application Note, Publication no. 5991-3649EN, pp. 5991-3649, 2013.

[21] N. Hadian, S. Hakim, and M. Nekoomanesh-Haghighi, "Storage time effect on dynamic structure of $\mathrm{MgCl}_{2}$. $\mathrm{nEtOH}$ adducts in heterogeneous Ziegler-Natta catalysts," Polyolefins Journal, vol. 1, pp. 33-41, 2014.

[22] R. Huang, F. Malizia, G. Pennini, C. E. Koning, and J. C. Chadwick, "Effects of $\mathrm{MgCl}_{2}$ crystallographic structure on active centre formation in immobilized single - centre and Ziegler-Natta catalysts for ethylene polymerization," Macromol. Rapid Commun., vol. 29, pp. 1732-1738, 2008.

[23] K. Thushara, T. Ajithkumar, P. Rajamohanan, and C. S. Gopinath, "Structural investigations of porous $\mathrm{MgCl}_{2}$-2-butanol molecular adduct as support for olefin polymerization," Appl. Catal., A., vol. 469, pp. 267-274, 2014.

[24] B. G. Song and S. K. Ihm, "The role of two different internal donors (phthalate and 1, 3-diether) on the formation of surface structure in $\mathrm{MgCl}_{2}$-supported Ziegler-Natta catalysts and their catalytic performance of propylene polymerization," J. Appl. Polym. Sci., vol. 131, 2014.

[25] A. Proto, L. Oliva, C. Pellecchia, A. J. Sivak, and L. A. Cullo, "Isotactic-specific polymerization of propene with supported catalysts in the presence of different modifiers," Macromolecules, vol. 23, pp. 2904-2907, 1990.

[26] M. Yamahiro, H. Mori, K.-H. Nitta, and M. Terano, "Electron donor-induced improvement of the microstructure of polypropene-block-poly (ethene-co-propene) synthesized by a modified stopped-flow polymerization method and correlation with its crystalline morphology," Polymer, vol. 40, pp. 5265-5272, 1999.

[27] Y. V. Kissin, "Main kinetic features of ethylene polymerization reactions with heterogeneous ZieglerNatta catalysts in the light of a multicenter reaction mechanism," J. Polym. Sci., Part A: Polym. Chem., vol. 39, pp. 1681-1695, 2001.

[28] M. A. Parvez, M. Rahaman, M. Suleiman, J. Soares, and I. Hussein, "Correlation of polymerization conditions with thermal and mechanical properties of polyethylenes made with Ziegler-Natta catalysts," Int. J. Polym. Sci., vol. 2014, 2014.

[29] L. H. Sperling, Introduction to Physical Polymer Science. John Wiley \& Sons, 2005.

[30] A. Munoz-Escalona and A. Parada, "Factors affecting the nascent structure and morphology of polyethylene obtained by heterogeneous Ziegler-Natta catalysts: 2. Crystallinity and melting behaviour," Polymer, vol. 20, pp. 859-866, 1979.

[31] M. I. Nikolaeva, T. B. Mikenas, M. A. Matsko, L. G. Echevskaya, and V. A. Zakharov, "Ethylene polymerization over supported titanium-magnesium catalysts: Effect of polymerization parameters on the molecular weight distribution of polyethylene," J. Appl. Polym. Sci., vol. 122, pp. 3092-3101, 2011.

[32] K. S. Ha, K. Y. Yoo, and H. K. Rhee, "Modeling and analysis of a slurry reactor system for heterogeneous olefin polymerization: The effects of hydrogen concentration and initial catalyst size," $J$. Appl. Polym. Sci., vol. 79, pp. 2480-2493, 2001. 